5 Purdue University, Dept. of Forestry and Natural Resources, Hardwood Tree Improvement and 6

20

21

22

23 flowering and homeotic alterations in transgenic Arabidopsis

\section{${ }^{1}$ Jun Hyung Lee}

Regeneration Center (HTIRC), 715 West State St., West Lafayette, IN 47907

and

${ }^{2}$ Paula M. Pijut

USDA Forest Service, Northern Research Station, HTIRC, 715 West State St., West Lafayette, IN 47907

Corresponding Author: Paula M. Pijut

Email:ppijut@purdue.edu

Phone: 1-765-496-2162

Fax: 1-765-494-9461

(1)

8

9

0

22 


\section{Abstract}

2 Reproductive sterility, which can be obtained by manipulating floral organ identity genes, is an

3 important tool for gene containment of genetically engineered trees. In Arabidopsis, AGAMOUS

$4 \quad(A G)$ is the only $\mathrm{C}$-class gene responsible for both floral meristem determinacy and floral organ

5 identity, and its mutations produce sterility. As a first step in an effort to develop transgenic

6 sterile black ash (Fraxinus nigra), an $A G$ ortholog in black ash (FnAG) was isolated using

7 reverse transcription polymerase chain reaction and rapid amplification of cDNA ends. Analysis

8 of the deduced amino acid sequence showed a typical MIKC structure of type II plant MADS-

9 box protein with a highly conserved MADS-domain. Phylogenetic analysis revealed that FnAG

10 had a close relationship with AG orthologs from other woody species. FnAG transcript was

11 mainly expressed in reproductive tissues, but rarely detected in the vegetative tissues, consistent

12 with the ABC model for floral development. A functional analysis was performed by ectopic

13 expression of $F n A G$ driven by the CaMV $35 \mathrm{~S}$ promoter in transgenic Arabidopsis. Transformed

14 plants showed homeotic conversions of carpeloid sepals and stamenoid petals. Curled leaves,

15 reduced plant size, and earlier flowering were also observed in transgenic Arabidopsis. These

16 data indicated that the $F n A G$ functions in the same way as $A G$ in Arabidopsis. These results

17 provide the framework for targeted genome editing of black ash, an ecologically and

18 economically important wetland species.

Keywords: AGAMOUS, black ash, ectopic expression, flowering, Fraxinus nigra, MADS. 


\section{Introduction}

2

3

4

Black ash (Fraxinus nigra Marsh.) is an economically and ecologically important hardwood species in northeastern North America. The wood is used for cabinets, paneling, flooring, and is preferred by Native Americans for making splints for basketry (Benedict 2001; Beasley and Pijut 2013). Black ash also provides food and habitat for wildlife (Leopold et al. 1998) and this species has a great ecological impact, especially in riparian ecosystems (Nisbet et al. 2015). Black ash flowers are perfect or dioecious; they occur in panicles that arise from leaf scar axils produced the previous year (Gucker 2005). The flowers appear before the leaves.

Emerald ash borer (EAB; Agrilus planipennis), an invasive wood-boring beetle from Asia, threatens all North American ash species including black ash with devastating economic and ecological impacts (Poland and McCullough 2006; Kovacs et al. 2011). In order to manage this aggressive pest and conserve Fraxinus spp., there have been numerous calls for genetically engineered ash trees resistant to the EAB. Concerns about transgene flow and its potential impact on the environment, however, limit the widespread acceptance and regulatory approval of transgenic trees (van Frankenhuyzen and Beardmore 2004). Reproductive sterility, obtained by disrupting flower development, is one of several efficient strategies for gene containment in transgenic crops and trees (Daniell 2002; Brunner et al. 2007).

Previous studies in model plants established the well-known ABC model to describe the genetic mechanism regulating flower development (Schwarz-Sommer et al. 1990; Coen and Meyerowitz 1991; Meyerowitz et al. 1991). This model proposed that three classes of homeotic genes act in combination to control floral organ identity: A-class alone controls the formation of sepals; A- and B-classes trigger petal development; B- and C-classes regulate the formation of stamens; and C-class alone directs the formation of carpels. The ABC model has been extended 
1 by adding D-class for ovule development (Angenent el al. 1995) and E-class which was required

2 for petal, stamen, and carpel development (Pelaz et al. 2000; Honma and Goto 2001). According

3 to the ABCDE model, MADS-box proteins interact with DNA to form multimeric complexes

4 that regulate the development of different floral organs (Honma and Goto 2001). MADS-box genes are a superfamily of transcription factors found in fungi, animals, and

6 plants. They are distinguished as type I and type II (Alvarez-Buylla et al. 2000; Gramzow et al.

7 2010). The type II MADS-box genes in plants encode MIKC-type proteins that consist of four

8 domains: a highly conserved MADS (M) domain for DNA binding; an intervening (I) domain for

9 the selective formation of DNA-binding dimers; a keratin $(\mathrm{K})$ domain for the formation of an

10 amphipathic helix that promotes protein-protein interaction; and the most variable region, the C-

11 terminal (C) domain, the function of which is not yet known (Theissen et al. 2000). There are

12 around 100 MADS-box genes in flowering plants, but $A G A M O U S(A G)$ is the only C-class gene

13 found in Arabidopsis. A flower of the Arabidopsis ag mutant shows petals and new flowers

14 instead of stamens and carpels, respectively, while overexpression of $A G$ induces homeotic

15 changes of sepals to carpels, and petals to stamen (apetala2 (ap2)-like phenotype) indicating that

$16 A G$ was involved in both floral meristem determinacy and floral organ identity (Yanofsky et al.

17 1990; Mizukami and Ma 1992). $A G$ homologs have been isolated and studied in a variety of

18 species including woody plants, such as poplar (Brunner et al. 2000), black cherry (Liu et al.

19 2010), green ash (Du and Pijut 2010), radiata pine (Liu 2012), London plane tree (Zhang et al.

20 2013), and pecan (Zhang et al. 2016). Ectopic expression of $A G$ homologs in transgenic plants

21 resulted in homeotic conversion of sepals and petals into carpels and stamens, respectively,

22 which confirmed their function as a C-class floral organ identity gene (Benedito et al. 2004; Du 
and Pijut 2010; Wang et al. 2012; Liu et al. 2013; Zhang et al. 2016). $A G$ homologs from black ash have not been described.

In the present study, an $A G$ ortholog from black ash $(F n A G)$ was isolated and characterized as a first step to achieve gene containment in transgenic black ash. Functional homology to $A G$ was tested by ectopic expression of $F n A G$ in Arabidopsis thaliana (with ap2like phenotype in the two outer floral whorls).

\section{Materials and methods}

\subsection{Plant materials}

Flowers and leaves were collected in April 2014 from mature male and female Fraxinus nigra trees at the Purdue Wildlife Area, Purdue University, and the Ross Hills Park, West Lafayette, IN, USA. Leaves and stems from in vitro shoot cultures of black ash maintained as described by Beasley and Pijut (2013) were also collected for RNA extraction. Samples were immediately frozen in liquid nitrogen and stored at $-80{ }^{\circ} \mathrm{C}$ until used for analysis.

Arabidopsis thaliana Col-0 ecotype seeds were obtained from the Arabidopsis Biological Resource Center (ABRC) at The Ohio State University, Columbus, OH, USA. Seeds were stratified for 3 days at $4{ }^{\circ} \mathrm{C}$ in the dark to break seed dormancy, and then sown onto Murashige and Skoog (1962) (MS; M499, PhytoTechnology Laboratories, Shawnee Mission, KS) medium supplemented with $10 \mathrm{~g} \mathrm{~L}^{-1}$ sucrose, $0.5 \mathrm{~g} \mathrm{~L}^{-1}$ 2-morpholinoethanesulfonic acid (MES), $8 \mathrm{~g} \mathrm{~L}^{-1}$ Bacto agar, pH 5.7 in $150 \times 15 \mathrm{~mm}$ petri dishes. Seeds germinated on agar medium were incubated at $25{ }^{\circ} \mathrm{C}$ under a $16 \mathrm{~h}$ photoperiod $\left(\sim 100 \mu \mathrm{mol} \mathrm{m}{ }^{-2} \mathrm{~s}^{-1}\right)$ provided by cool-white fluorescent bulbs. The germinated seedlings were grown for 2 weeks, and then transferred to water-saturated soil in pots covered with a plastic film to maintain high humidity and placed in the greenhouse under long-day conditions. The plastic film was removed after 2 days. 


\subsection{Isolation of an $A G$ ortholog from black ash}

2 Total RNA was extracted from the leaves of in vitro shoot cultures using the RNeasy Plant Mini Kit (Qiagen, Valencia, CA, USA) according to manufacturer's instructions. Re-suspended RNA was treated with DNase I (Thermo Fisher Scientific, Grand Island, NY, USA) in order to remove genomic DNA, and the first-strand cDNA was synthesized from $1 \mu \mathrm{g}$ total RNA using SuperScript III First-Strand Synthesis System (Thermo Fisher Scientific) and an oligo-dT primer. Degenerate primers AGP1 and AGP2 (Table 1) were designed based on other AG nucleotide sequences to amplify the internal fragment spanning part of the MADS-domain and the Kperformed with a $25 \mu 1$ PCR mixture containing $2.5 \mu 1$ 10× PCR buffer (5 PRIME, Gaithersburg, MD, USA), $1 \mu 110$ mM dNTP, $1 \mu 110 \mu \mathrm{M}$ AGP1 and AGP2 primers, respectively, $2 \mu 1$ cDNA, and $0.25 \mu 15 \mathrm{U}^{-1} \mathrm{l}^{-1}$ Taq polymerase (5 PRIME). The cycling program consisted of an initial for $1 \mathrm{~min}, 35$ additional cycles of $94{ }^{\circ} \mathrm{C}$ for $30 \mathrm{~s}, 47^{\circ} \mathrm{C}$ for $30 \mathrm{~s}, 72^{\circ} \mathrm{C}$ for $1 \mathrm{~min}$, and a final extension at $72{ }^{\circ} \mathrm{C}$ for $10 \mathrm{~min}$. A single strong band of expected size (258-bp) was purified with QIAquick Gel Extraction Kit (Qiagen), and was then cloned into pGEM-T Easy vector (Promega, Fitchburg, WI, USA) for sequencing at the Purdue University Genomic Center (West Lafayette, IN, USA). Based on the partial internal sequence of $F n A G$, two sets of gene specific primers were designed to perform 5'- and 3'-rapid amplification of cDNA ends (RACE) (FirstChoice RLM-RACE; Life Technologies, Grand Island, NY, USA). For the first-round PCR, AGP3 and AGP4 (Table 1) were used as 5'- and 3'-RACE outer primers, respectively. For the second-round PCR, AGP5 and AGP6 (Table 1) were used as 5'- and 3'-RACE inner primers, respectively. The obtained fragments from the second round PCR were cloned into pGEM-T Easy vectors for 
sequencing, and then assembled to determine the full-length cDNA sequence. To amplify a complete coding sequence (CDS) and genomic sequence of $F n A G$, the first-strand cDNA and genomic DNA were used as a template, respectively, for PCR using AGP7 and AGP8 (Table 1) as forward and reverse primers, respectively. Unless noted otherwise, all PCR reactions were performed using Phusion High-Fidelity DNA polymerase (New England Biolabs, Ipswich, MA, USA) according to manufacturer's instructions for PCR mixture preparations, and all the cycling programs consisted of an initial denaturation at $98{ }^{\circ} \mathrm{C}$ for $30 \mathrm{~s}$, followed by 35 cycles of $98{ }^{\circ} \mathrm{C}$ for $10 \mathrm{~s}, 58{ }^{\circ} \mathrm{C}$ for $30 \mathrm{~s}, 72{ }^{\circ} \mathrm{C}$ for $1 \mathrm{~min}$, and a final extension at $72{ }^{\circ} \mathrm{C}$ for $10 \mathrm{~min}$. The gene structure was determined by aligning the CDS and genomic DNA sequence of FnAG.

\subsection{Phylogenetic analyses}

The deduced amino acid sequence of $F n A G$ was used to search for $A G$ homologs from other plants by BLASTX, and then all sequences were aligned by ClustalW (Larkin et al. 2007). A phylogenetic tree was constructed using the neighbor-joining method in MEGA5 software (Tamura et al. 2011). Bootstrap values were derived from 1,000 replicate runs. GenBank accession numbers of amino acid sequences used were as follows: GAG2 (Q40872; Panax ginseng), CaMADS (ADU56831; Coffea arabica), NAG1 (Q43585; Nicotiana tabacum), NbAG (AFK13159; N. benthamiana), CaAGL2 (ADP06386; Capsicum annuum), pMADS3 (Q40885; Petunia hybrida), SiAG (AIS82595; Sesamum indicum), CsAG (ADP02394; Citrus sinensis), FpAG (AFP99884; F. pennsylvanica), VvAG (NP_001268097; Vitis vinifera), AGAMOUS (X53579; A. thaliana), JcAG (NP_001292936; Jatropha curcas), PtAG1 (AF052570; Populus trichocarpa), PtAG2 (AF052571; P. hybrida), TcAG (XP_007025251; Theobroma cacao), PsAG (EU938540.1; P. serotina), PpMADS4 (AAU29513; $P$. persica), PmAG (ABU41518; $P$. mume), PLE (BAI68391; Antirrhinum majus), AGL1/SHP1 (AEE79831.1; A. thaliana), 
2 (AAM21345.1; V. vitis), MdMADS10 (NP_001280931.1; Malus domestica), AGL11/STK

4 Phytolacca americana), and SxcAG2 (AAS45704.1; Micranthes careyana).

6 To analyze the relative expression of $F n A G$, semi-quantitative RT-PCR and real-time PCR

7 (qPCR) were performed. Total RNAs were extracted from vegetative tissues (leaves and in vitro

8 shoot cultures) and reproductive tissues (male and female flowers) of black ash using the RNeasy

9 Plant Mini Kit (Qiagen). DNase I (Thermo Fisher Scientific) treated RNA was then used in RTPCR to synthesize first-strand cDNA using SuperScript III First-Strand Synthesis System

11 (Thermo Fisher Scientific) and an oligo-dT primer. The qPCR was performed with $20 \mu 1$ reaction 12 solution containing $1 \mu \mathrm{l}$ cDNA, $10 \mu \mathrm{M}$ AGP3 and AGP6, and iTaq ${ }^{\mathrm{TM}}$ Universal SYBR $^{\circledR}$ Green 13 Supermix (Bio-Rad, Hercules, CA, USA). The cycling conditions consisted of DNA polymerase activation at $95^{\circ} \mathrm{C}$ for $60 \mathrm{~s}, 40$ cycles of $95{ }^{\circ} \mathrm{C}$ for $10 \mathrm{~s}, 57^{\circ} \mathrm{C}$ for $20 \mathrm{~s}, 72{ }^{\circ} \mathrm{C}$ for $30 \mathrm{~s}$, and

15 followed by a melting curve analysis from 65 to $95{ }^{\circ} \mathrm{C}$ performed with the CFX Connect ${ }^{\mathrm{TM}}$ Real16 Time PCR Detection System (Bio-Rad). Relative transcript levels for mRNAs were obtained 17 using the comparative cycle threshold $\left(C_{\mathrm{t}}\right)$ method and normalized to translation elongation 18 factor alpha $(e E F A \alpha)$ from black ash (Rivera-Vega et al. 2012). Each reaction had three 19 biological replicates and was repeated twice.

\section{2.5. Functional analysis of FnAG through transformation of Arabidopsis thaliana}

21 A binary vector pBI121 was used for FnAG insertion and overexpression in Arabidopsis. The

22 GUS gene in pBI121 was replaced by the CDS sequence of FnAG which was driven by the

23 CaMV 35S promoter. The $35 S:: F n A G$ construct and the empty pBI121 vector as a control were 
transformed into Agrobacterium tumefaciens strain GV3101 by electroporation (Mattanovich et al. 1989), and then introduced into the wild-type $A$. thaliana ecotype Col-0 via the floral dip method (Zhang et al. 2006). $\mathrm{T}_{1}$ seeds were placed onto agar plates containing MS medium with

$50 \mathrm{mg} \mathrm{L}^{-1}$ kanamycin as selection agent. The seedlings were screened for $2-3$ weeks on the plate and then kanamycin-resistant lines were transferred to water-saturated soil in pots. The integration of $F n A G$ in the transgenic lines was confirmed by PCR using AGP3 and AGP4 primers. The number of days from planting to the first flower and the number of rosette leaves at that stage were recorded in $\mathrm{T}_{3}$ plants. Statistical differences were assessed via analysis of variance with the $\operatorname{SAS}^{\circledR} 9.3$ software package $\left(\mathrm{SAS}^{\circledR}\right.$ Institute 2011).

\subsection{Expression analysis of AtAG and FnAG in transgenic Arabidopsis}

Floral tissues were collected from seven transgenic lines and wild-type Arabidopsis. The qPCR was performed as previously described. Primers, AtAG1 and AtAG2 (Table 1) were designed to amplify endogenous $A G$, and AGP3 and AGP6 were used to amplify ectopically expressed FnAG. Relative transcript levels for mRNAs were obtained using the $C_{\mathrm{t}}$ method and normalized to ACTIN2 from Arabidopsis (AtActin1 and AtActin2 as forward and reverse primers, respectively). Each reaction had three biological replicates and was repeated twice.

\section{Results}

\subsection{Isolation and sequence analysis of an AG ortholog from black ash}

In order to isolate the $A G$ ortholog from black ash, RT-PCR was performed using degenerate primers developed based on highly conserved sequence from a total of $17 A G$ homologs. An expected 258-bp internal fragment was amplified and sequenced (data not shown) to design specific primers for RACE. The results of $5^{\prime}-$ and $3^{\prime}-\mathrm{RACE}$ revealed that $F n A G$ cDNA was 1022-bp in length with a $5^{\prime}$ untranslated region (UTR) of 67-bp and a $3^{\prime}$ UTR of 226-bp 
upstream of the poly(A) tail. A 4578-bp genomic sequence was obtained and the alignment analysis of cDNA and genomic sequence showed that $F n A G$ consisted of nine exons and eight introns (Fig. 1a). FnAG encodes a putative type II plant MADS-box protein of 242 amino acids containing N-, MADS-, I-, K-, and C-domains. It also contains two short, highly conserved regions, called AG motif I and AG motif II in the C-domain, as reported for other AG homologs (Kramer et al. 2004). A comparison of deduced amino acid sequence of $F n A G$ and $A G$ homologs from other woody species showed a highly conserved 56 residue MADS-domain (Fig. 1b).

FnAG shared greater than $96 \%$ amino acid identity to the other AG homologs within the MADSdomain. In addition to the MADS-domain, regions including I- and K-domains were also conserved among FnAG and other AG homologs (Fig. 1b). Overall, FnAG was most similar to FpAG from $F$. pennsylvanica, showing $94 \%$ identity, followed by $81 \%$ identity with GAG2 from Panax ginseng, 77\% with PtAG2 from Populus trichocarpa, 75\% with PsAG from Prunus serotina and PtAG1, 74\% with PpMADS4 from Prunus persica, and 68\% with AG from Arabidopsis thaliana and MdAG from Malus domestica. A phylogenetic tree was constructed using the deduced amino acid sequence of $F n A G$ and 28 other MADS-box proteins (Fig. 2). Phylogenetic analysis placed $F n A G$ within the clade of C-lineage $A G$ subfamily genes, showing high bootstrap support for a close relationship with SiAG from Sesamum indicum and CsAG from Citrus sinensis.

\subsection{Expression analysis of FnAG in black ash tissues}

The spatial expression of $F n A G$ was investigated in various vegetative and reproductive tissues using semi-quantitative RT-PCR (Fig. 3a). Gene-specific primers were used to amplify the 183bp long internal fragment of $F n A G$. Amplification of an $e E F A \alpha$ fragment was used as a constitutively expressed gene control to enable inter-sample comparisons. The transcripts of 
$1 F n A G$ were detected in the female and male flowers and in vitro shoot cultures, but only rarely in

2 leaves. The steady state levels of $F n A G$ in reproductive tissues were higher than in in-vitro shoot

3 cultures, showing a higher relative intensity of amplified product. The relative mRNA expression

4 level of $F n A G$ was also examined by qPCR (Fig. 3b). The mRNA levels of $F n A G$ were 25.8- and

5 13.5-fold higher in female and male flowers, respectively, than in leaves. Its level in in-vitro

6 shoot cultures was 2.3 -fold higher than in leaves.

7 3.3. Ectopic expression of FnAG in Arabidopsis

8 We used ectopic expression of FnAG CDS in Arabidopsis to determine whether FnAG could

9 function as $A G$. A binary vector pBI121 containing $35 S:: F n A G$ and neomycin

10 phosphotransferase II (nptII) gene was introduced into Arabidopsis ecotype Col-0 via

11 Agrobacterium transformation. Among a total of 17 kanamycin-resistant $\mathrm{T}_{1}$ plants, the presence

12 of $F n A G$ was confirmed from seven independent plants (data not shown) and these were used to

13 generate $\mathrm{T}_{3}$ plants for phenotyping. Phenotypic alterations were observed in $F n A G$ -

14 overexpressing plants (Fig. 4). The most prominent changes in the $F n A G$-overexpressing

15 transgenic plants were the homeotic modifications in the first and second whorls of flowers.

16 Compared to wild-type flowers consisting of four sepals, four petals, six stamens, and a pistil

17 (Fig. 4a), transgenic flowers displayed petals transformed into stamen-like structures (Fig. 4b),

18 and sepals converted into carpel-like structures (Fig. 4c). Third and fourth whorls developed

19 normally, resulting in fertility. The $35 S:: F n A G$ plants also showed small and curled leaves (Fig.

20 4d), immature early flowers with sepals which failed to enclose flower buds (Fig. 4e), and

21 reduced plant size (Fig. 4f). FnAG-overexpressing plants flowered significantly earlier than wild-

22 type and empty-vector control plants (Fig. 4g-i). 

into two groups (Fig. 5). Although plants with weak ap2-like phenotype (Fig. 5b) showed relatively normal vegetative growth compared to strong phenotype plants (Fig. 5a), they displayed smaller plant size than wild-type plants (Fig. 5c). Plants with strong phenotype produced first flowers 12.62 days earlier (with 5.19 rosette leaves) than the wild-type, while

6 plants with weak phenotypic alteration produced first flowers 6.83 days earlier (with 10.1 rosette

7 leaves) than the wild-type (Table 2). The FnAG mRNA expression level was higher in the strong 8 phenotype group (\#1, \#3, \#4, and \#6) than that in the weak phenotype group (\#2, \#5, and \#7) (Fig.

9 6a). The endogenous $A t A G$ mRNA expression, however, was not significantly different among 10 plants in all groups (Fig. 6b).

\section{4. Discussion}

12 During the diversification of the $A G$ subfamily genes in angiosperms, gene duplication and

13 functional evolution have occurred, giving rise to the C- and D-lineage (Kramer et al. 2004).

14 Thus, the D-lineage genes such as $\operatorname{SEEDSTICK}$ (STK; formerly known as $A G L 11$ ) also belong to 15 the $A G$ subfamily and were preferentially recruited for ovule development (Dreni and Kater 16 2014). Subsequent duplications in the C-lineage have led to paralogous lineages of PLENA (PLE)

17 from Antirrhinum and euAG from Arabidopsis, maintaining functional redundancy (Kramer et al.

18 2004). Although PLE C-lineage genes in Arabidopsis, such as SHATTERPROOF1 (SHP1) and SHP2 (formerly known as $A G L 1$ and $A G L 5$, respectively), are similar to $A G$ in function, they

20 were not expressed in the meristem and primordial cells at the appropriate time, so $A G$ was the 21 only fully functional C-class gene (Dreni and Kater 2014). In the present study, phylogenetic

22 analysis confirmed that $F n A G$ was placed within the eu $A G \mathrm{C}$-lineage clade, indicating that $F n A G$ 23 was associated with C-function of $A G$. 
$F n A G$ showed typical gene structure; the position and number of introns in FnAG was conserved with respect to other $A G$ homologs (Brunner et al. 2000; Kramer et al. 2004). Unlike other MIKC-type MADS-box genes that have six introns, genes in the C-lineage of $A G$ subfamily including $F n A G$ have two additional introns positioned $5^{\prime}$ of the MADS domain and in the last codon of AG motif II (Kramer et al. 2004). In FnAG, the second intron was about $2 \mathrm{~kb}$ spanning the largest part of the gene, which might contain functionally important regulatory sequences for controlling its expression specifically to stamens and carpels. Previous studies in Arabidopsis demonstrated that the second intron contains cis-regulatory elements that are the binding sites of activators such as LEAFY and WUSCHEL, or repressors such as AP2 or LEUNIG, to control $A G$ expression (Sieburth and Meyerowitz 1997; Deyholos and Sieburth 2000; Hong et al. 2003). This binding motif was also highly conserved in poplar (Brunner el al. 2000). It has been suggested that using the enhancer element in the second intron of $A G$ could produce complete sterility in Arabidopsis and tobacco through tissue-specific ablation of stamens and carpels (Liu and Liu 2008; Wang et al. 2008). Although we did not study this regulatory element in detail, this approach would likely be a practical method to achieve gene containment in transgenic trees.

A previous study revealed that there was only one $A G$ homolog in green ash (Du and Pijut 2010). A BLAST search of FnAG against the European ash (F. excelsior) genome (www.ashgenome.org) showed that European ash may contain two $A G$ homologs (personal communication with Richard Buggs, Queen Mary University of London).

The deduced amino acid sequence of FnAG revealed extensive sequence similarity with other AG proteins. As a major determinant of DNA binding, the MADS-domain was highly conserved in FnAG. As was found for AG and proteins of AG homologs, FnAG included an 
additional peptide extension of 17 amino acid residues at the N-terminal before the MADS

2 domain (Fig. 1b). The N-terminal extension peptide, however, does not appear to affect AG

3 activity, because proteins of some AG homologs that lack this extension, such as LLAG1 in lily,

4 HpAG in Hosta plantaginea, and CiAG in pecan, function normally (Mizukami et al. 1996;

5 Benedito et al. 2004; Wang et al. 2012, Zhang et al. 2016). The I- and K-domains of FnAG were

6 moderately conserved, but showed high sequence similarity to those of $F p A G$. According to

7 Pnueli et al. (1994), in this region, tomato showed a closer relationship with tobacco than

8 Brassicaceae, and Antirrhinum was more closely related to the Solanaceae than Brassicaceae,

9 suggesting the apparent evolutionary relationship between species in this region.

The C-domain is the most variable region and its function has not yet been elucidated.

11 Studies of truncated AG protein lacking the C-domain, however, showed ag-like phenotype,

12 indicating that the truncated AG protein inhibits normal AG function (Mizukami et al. 1996).

13 Complete male sterility was obtained only in transgenic tobacco ectopically expressing truncated

14 PrAG1 protein without the K- and C-domain, but not in lines expressing the full-length protein,

15 indicating that the $\mathrm{C}$ domain or $\mathrm{C}$ plus $\mathrm{K}$ domains may affect the MADS dimer formation

16 between PrAG1 and NAG1 (Liu 2012). In Prunus lannesiana, a 170-bp exon skip caused by

17 abnormal splicing deleted the C-domain AG motifs I and II. The result was a double-flowered

18 phenotype in which stamens and carpels were converted to petaloid organs (Liu et al. 2013).

19 Overall, the C-domain is functionally important, and it could be involved in transcriptional

20 activation or higher-order protein interactions for the formation of multimeric transcription factor

21 complexes (Theissen et al. 2000; Kramer et al. 2004).

In addition to evidence from amino acid sequence analyses of FnAG, the steady state

23 transcript pattern of $F n A G$ strongly indicated that $F n A G$ was the ortholog of $A G$. The spatial 
1 pattern of transcript abundance for $F n A G$, specifically its abundance in reproductive tissues,

2 corresponded with that of Arabidopsis $A G$ and other $A G$ homologous genes (Yanofsky et al.

3 1990; Du and Pijut 2010; Liu 2012; Zhang et al. 2013). Although $F n A G$ transcripts were also

4 detected in vegetative tissues, as observed in poplar (Brunner et al. 2000) and pecan (Zhang et al.

5 2016), the steady state levels in vegetative tissue were significantly lower than in reproductive

6 tissues.

7 In nature, double-flowered mutants provide strong evidence that homeotic mutant

8 phenotypes of this class derive from mutations in $A G$ homologous genes. A study with a double-

9 flowered ranunculid mutant 'Double White' revealed that the insertion of a retrotransposon

10 within the putative $A G$ ortholog ThtAGl caused either nonsense-mediated decay of transcripts or

11 alternative splicing that resulted in mutant proteins with K-domain deletions (Galimba et al.

12 2012). Loss of C-domain AG motifs I and II in PreAG caused by abnormal splicing produced the

13 double-flowered cultivar of Prunus lannesiana (Liu et al. 2013). Even though there were no

14 significant differences between the double-flowered cultivar and wild-type plants in promoter

15 and intron sequences, the level of TrimAG transcript was reduced in the double-flowered

16 Tricyrtis macranthopsis cultivar, indicating it might derive from a mutation in one of the genes

17 in the regulatory network that controls $\operatorname{Trim} A G$ expression or, alternatively, transcriptional

18 silencing by methylation of TrimAG promoter/intron sequences (Sharifi et al. 2015).

The function of isolated $A G$ homologs usually has been examined by ectopic expression

20 in model plants to see if the transgenic plants showed homeotic alteration. That was because

21 complementation analysis was more difficult, as the null-mutant of $A G$ was completely sterile.

22 However, not all $A G$ homologous genes cause the typical homeotic alteration of ap2-like

23 phenotype in transgenic plants when ectopically overexpressed. The ectopic expression of 
NTAG1 from Chinese narcissus rarely produced the homeotic floral phenotype, especially as the

2 generation of transgenic plants increased (Deng et al. 2011). Liu (2012) also found no

3 phenotypic effect on floral development from transgenic tobacco plants with ectopic expression

4 of PrAG1. This could be because there were different interacting cofactors in ectopic tissues, or

5 endogenous genes in transformed plants masked the functionality of $A G$ homologs from other

6 species (Liu 2012). The long juvenility of black ash (10-15 years) significantly complicates

7 transgenic evaluation of flowering gene action within the species. Therefore, in the present study,

8 we used Arabidopsis for the functional analysis of $F n A G$. The ectopic expression of $F n A G$ in

9 transgenic Arabidopsis induced homeotic conversions of carpeloid sepals and stamenoid petals,

10 curled leaves, reduced plant size, and prematurely terminated inflorescences, as has been

11 reported for other $A G$ homologs (Du and Pijut 2010; Wang et al. 2012; Liu et al. 2013). The

12 transgenic plants also showed accelerated flowering: 12.62 and 6.83 days earlier in strong and

13 weak phenotypes, respectively, than wild-type. Ectopic expression of the GmGAL2, a soybean

14 AGAMOUS Like 2, enhanced flowering in transgenic Arabidopsis regardless of the photoperiod

15 by promoting the expression of key flowering genes CONSTANS (CO) and FLOWERING

16 LOCUS T(FT), and suppressing floral inhibitor FLOWERING LOCUS C (FLC) (Xu et al. 2010).

\section{5. Conclusions}

18 In summary, an $A G$ ortholog was cloned from black ash and its function in floral organ identity was analyzed. Sequence analysis and expression analysis showed that $F n A G$ was closely related to the other $A G$ homologs with transcript expression specifically in the reproductive tissues.

$21 F n A G$ was involved in floral organ identity, as expected for a functional homolog of $A G$ in black

22 ash. Based on these data, we conclude that $F n A G$ is a strong candidate for the black ash

23 functional ortholog of Arabidopsis $A G$, and we believe $F n A G$ will be an excellent target for 
1 genome editing to produce transgenic sterile black ash. Our goal is to manipulate FnAG using a

2 targeted genome modification technique -clustered regularly interspaced short palindromic

3 repeats (CRISPR)/CRISPR-associated (Cas) system- for production of sterile black ash.

4 CRISPR/Cas9 constructs targeting $F n A G$ are being developed and transformation is currently

5 underway.

\section{Acknowledgements}

7 This research was supported by partial funding from the USDA-APHIS-PPQ Center for Plant

8 Health Science and Technology, the U.S. Endowment for Forestry and Communities, and

9 members of the Indiana Hardwood Lumbermen's Association.

11 Mention of a trademark, proprietary product, or vendor does not constitute a guarantee or

12 warranty of the product by the U.S. Department of Agriculture and does not imply its approval to

13 the exclusion of other products or vendors that also may be suitable.

14

15 Data Archiving Statement

16 Sequence data for FnAG have been archived in GenBank under accession number KX592173.

17

18

19

20

21

22

23 
1

2 Alvarez-Buylla, E.R., Pelaz, S., Liljegren, S.J., Gold, S.E., Burgeff, C., Ditta, G.S., Ribas de

3 Pouplana, L., Martínez-Castilla, L., Yanofsky, M.F. 2000. An ancestral MADS-box gene

4 duplication occurred before the divergence of plants and animals. Proc. Natl. Acad. Sci. USA

$597,5328-5333$.

6 Angenent, G.C., Franken, J., Busscher, M., van Dijken, A., van Went, J.L., Dons, H.J., van

7 Tunen, A.J. 1995. A novel class of MADS box genes is involved in ovule development in

$8 \quad$ petunia. Plant Cell 7, 1569-1582.

9 Beasley, R.R., Pijut, P.M. 2013. Regeneration of plants from Fraxinus nigra Marsh. hypocotyls.

10 HortScience 48, 887-890.

11 Benedict, M.A. 2001. Black ash: Its use by Native Americans, site factors affecting seedling

12 abundance and ring growth in northern Minnesota. MS thesis, Univ. of Minnesota, St. Paul, 13 MN.

14 Benedito, V.A., Visser, P.B., van Tuyl, J.M., Angenent, G.C., de Vries, S.C., Krens, F.A. 2004.

15 Ectopic expression of LLAG1, an AGAMOUS homologue from lily (Lilium longiflorum

16 Thunb.) causes floral homeotic modifications in Arabidopsis. J. Exp. Bot. 55, 1391-1399.

17 Brunner, A., Li, J., DiFazio, S., Shevchenko, O., Montgomery, B., Mohamed, R., Wei, H., Ma,

18 C., Elias, A., VanWormer, K., Strauss, S. 2007. Genetic containment of forest plantations.

19 Tree Genet. Genomes 3, 75-100.

20

21

22
Brunner, A.M., Rottmann, W.H., Sheppard, L.A., Krutovskii, K., DiFazio, S.P., Leonardi, S., Strauss, S.H. 2000. Structure and expression of duplicate AGAMOUS orthologues in poplar. Plant Mol. Biol. 44, 619-634. 
1 Coen, E.S., Meyerowitz, E.M. 1991. The war of the whorls: genetic interactions controlling

2 flower development. Nature 353, 31-37.

3 Daniell, H. 2002. Molecular strategies for gene containment in transgenic crops. Nat. Biotechnol.

$4 \quad 20,581-586$.

5 Deng, X., Xiong, L., Wang, Y., Sun, Y., Li, X. 2011. Ectopic expression of an AGAMOUS

6 homolog NTAG1 from Chinese narcissus accelerated earlier flowering and senescence in

$7 \quad$ Arabidopsis. Mol. Plant Breeding 2, 14-21.

8 Deyholos, M.K., Sieburth, L.E. 2000. Separable whorl-specific expression and negative

$9 \quad$ regulation by enhancer elements within the AGAMOUS second intron. Plant Cell 12, 1799-

101810.

11 Dreni, L., Kater, M.M. 2014. MADS reloaded: evolution of the AGAMOUS subfamily genes.

$12 \quad$ New Phytol. 201, 717-732.

13 Du, N., Pijut, P.M. 2010. Isolation and characterization of an AGAMOUS homolog from

$14 \quad$ Fraxinus pennsylvanica. Plant Mol. Biol. Rep. 28, 344-351.

15 Galimba, K.D., Tolkin, T.R., Sullivan, A.M., Melzer, R., Theißen, G., Di Stilio, V.S. 2012. Loss

16 of deeply conserved C-class floral homeotic gene function and C-and E-class protein

17 interaction in a double-flowered ranunculid mutant. Proc. Natl. Acad. Sci. 109, E2267-E2275.

18 Gramzow, L., Ritz, M.S., Theißen, G. 2010. On the origin of MADS-domain transcription

19 factors. Trends Genet. 26, 149-153.

20 Gucker, C.L. 2005. Fraxinus nigra. In: Fire Effects Information System, [Online]. U.S.

21 Department of Agriculture, Forest Service, Rocky Mountain Research Station, Fire Sciences

22 Laboratory (Producer). Available: http://www.feis-crs.org/feis/ 
1 Hong, R.L., Hamaguchi, L., Busch, M.A., Weigel, D. 2003. Regulatory elements of the floral

2 homeotic gene AGAMOUS identified by phylogenetic footprinting and shadowing. Plant Cell

$3 \quad 15,1296-1309$.

4 Honma, T., Goto, K. 2001. Complexes of MADS-box proteins are sufficient to convert leaves

5 into floral organs. Nature 409, 525-529.

6 Kovacs, K.F., Mercader, R.J., Haight, R.G., Siegert, N.W., McCullough, D.G., Liebhold, A.M.

7 2011. The influence of satellite populations of emerald ash borer on projected economic costs

8 in U.S. communities, 2010-2020. J. Environ. Manage. 92, 2170-2181.

9 Kramer, E.M., Jaramillo, M.A., Di Stilio, V.S. 2004. Patterns of gene duplication and functional 10 evolution during the diversification of the AGAMOUS subfamily of MADS box genes in 11 angiosperms. Genetics 166, 1011-1023.

12 Larkin, M.A., Blackshields, G., Brown, N.P., Chenna, R., McGettigan, P.A., McWilliam, H., 13 Valentin, F., Wallace, I.M., Wilm, A., Lopez, R., Thompson, J.D., Gibson, T.J., Higgins, D.G.

14 2007. Clustal W and Clustal X version 2.0. Bioinformatics 23, 2947-2948.

15 Leopold, D.J., McComb, W.C., Muller, R.N. 1998. Trees of the central hardwood forests of 16 North America. Timber Press, Portland, OR.

17 Liu, J.J. 2012. Ectopic expression of a truncated Pinus radiata AGAMOUS homolog (PrAG1) 18 causes alteration of inflorescence architecture and male sterility in Nicotiana tabacum. Mol. 19 Breeding 30, 453-467.

20 Liu, X., Anderson, J., Pijut, P.M. 2010. Cloning and characterization of Prunus serotina 21 AGAMOUS, a putative flower homeotic gene. Plant Mol. Biol. Rep. 28, 193-203.

22 Liu, Z., Liu, Z. 2008. The second intron of AGAMOUS drives carpel- and stamen-specific 23 expression sufficient to induce complete sterility in Arabidopsis. Plant Cell Rep. 27, 855-863. 
Liu, Z., Zhang, D., Liu, D., Li, F., Lu, H. 2013. Exon skipping of AGAMOUS homolog PrseAG in developing double flowers of Prunus lannesiana (Rosaceae). Plant Cell Rep. 32, 227-237.

Mattanovich, D., Rüker, F., Machado, A.C., Laimer, M., Regner, F., Steinkellner, H., Himmler, G., Katinger, H. 1989. Efficient transformation of Agrobacterium spp. by electroporation. Nucleic Acids Res. 17, 6747.

Meyerowitz, E.M., Bowman, J.L., Brockman, L.L., Drews, G.N., Jack, T., Sieburth, L.E., Weigel, D. 1991. A genetic and molecular model for flower development in Arabidopsis thaliana. Development 113, 157-167.

Mizukami, Y., Huang, H., Tudor, M., Hu, Y., Ma, H. 1996. Functional domains of the floral regulator AGAMOUS: characterization of the DNA binding domain and analysis of dominant negative mutations. Plant Cell 8, 831-845.

Mizukami, Y., Ma, H. 1992. Ectopic expression of the floral homeotic gene AGAMOUS in transgenic Arabidopsis plants alters floral organ identity. Cell 71, 119-131.

Murashige, T., Skoog, F. 1962. A revised medium for rapid growth and bioassays with tobacco tissue cultures. Physiol. Plant 15, 473-497.

Nisbet, D., Kreutzweiser, D., Sibley, P., Scarr, T. 2015. Ecological risks posed by emerald ash borer to riparian forest habitats: A review and problem formulation with management implications. Forest Ecol. Manage. 358, 165-173.

Pelaz, S., Ditta, G.S., Baumann, E., Wisman, E., Yanofsky, M.F. 2000. B and C floral organ identity functions require SEPALLATA MADS-box genes. Nature 405, 200-203.

Pnueli, L., Hareven, D., Rounsley, S.D., Yanofsky, M.F., Lifschitz, E. 1994. Isolation of the tomato AGAMOUS gene TAG1 and analysis of its homeotic role in transgenic plants. Plant Cell 6, 163-173. 
Poland, T.M., McCullough, D.G. 2006. Emerald ash borer: Invasion of the urban forest and the

2 threat to North America's ash resource. J. Forestry 104, 118-124.

3 Rivera-Vega, L., Mamidala, P., Koch, J.L., Mason, M.E., Mittapalli, O. 2012. Evaluation of

4 reference genes for expression studies in ash (Fraxinus spp.). Plant Mol. Biol. Rep. 30, 242-

5245.

$6 \quad$ SAS $^{\circledR}$ Institute Inc. 2011. SAS ${ }^{\circledR} 9.3$ software package, Cary, NC, USA.

7 Schwarz-Sommer, Z., Huijser, P., Nacken, W., Saedler, H., Sommer, H. 1990. Genetic control of

$8 \quad$ flower development by homeotic genes in Antirrhinum majus. Science 250, 931.

9 Sharifi, A., Oizumi, K., Kubota, S., Bagheri, A., Shafaroudi, S.M., Nakano, M., Kanno, A. 2015.

10 Double flower formation in Tricyrtis macranthopsis is related to low expression of

11 AGAMOUS ortholog gene. Sci. Horti. 193, 337-345.

12 Sieburth, L.E., Meyerowitz, E.M. 1997. Molecular dissection of the AGAMOUS control region

13 shows that cis elements for spatial regulation are located intragenically. Plant Cell 9, 355-365.

14 Tamura, K., Peterson, D., Peterson, N., Stecher, G., Nei, M., Kumar, S. 2011. MEGA5:

15 molecular evolutionary genetics analysis using maximum likelihood, evolutionary distance,

16 and maximum parsimony methods. Mol. Biol. Evol. 28, 2731-2739.

17 Theissen, G., Becker, A., Rosa, A.D., Kanno, A., Kim, J.T., Münster, T., Winter, K.-U., Saedler,

18 H. 2000. A short history of MADS-box genes in plants. Plant Mol. Biol. 42, 115-149.

19 van Frankenhuyzen, K., Beardmore, T. 2004. Current status and environmental impact of

20 transgenic forest trees. Can. J. Forest Res. 34, 1163-1180.

21 Wang, H.Z., Hu, B., Chen, G.P., Shi, N.N., Zhao, Y., Yin, Q.C., Liu, J.J. 2008. Application of

22 Arabidopsis AGAMOUS second intron for the engineered ablation of flower development in

23 transgenic tobacco. Plant Cell Rep. 27, 251-259. 
1 Wang, Y., Zhang, X., Liu, Z., Zhang, D., Wang, J., Liu, D., Li, F., Lu, H. 2012. Isolation and

2 characterization of an AGAMOUS-like gene from Hosta plantaginea. Mol. Biol. Rep. 39, $3 \quad 2875-2881$.

4 Xu, J., Zhong, X., Zhang, Q., Li, H. 2010. Overexpression of the GmGAL2 gene accelerates 5 flowering in Arabidopsis. Plant Mol. Biol. Rep. 28, 704-711.

6 Yanofsky, M.F., Ma, H., Bowman, J.L., Drews, G.N., Feldmann, K.A., Meyerowitz, E.M. 1990.

7 The protein encoded by the Arabidopsis homeotic gene AGAMOUS resembles transcription 8 factors. Nature 346, 35-39.

9 Zhang, J., Li, Z., Guo, C., Liu, G., Bao, M. 2013. Isolation and functional analyses of a putative 10 floral homeotic C-function gene in a basal eudicot London plane tree (Platanus acerifolia). 11 PLoS ONE 8:e63389.

12 Zhang, J., Wang, M., Mo, Z., Wang, G., Guo, Z. 2016. Molecular characterization and functional 13 analysis of an AGAMOUS-like gene CiAG from pecan. HortScience 51, 664-668.

14 Zhang, X., Henriques, R., Lin, S.-S., Niu, Q.-W., Chua, N.-H. 2006. Agrobacterium-mediated 15 transformation of Arabidopsis thaliana using the floral dip method. Nat. Protoc. 1, 641-646. 16 17 18 19 20 21 22 23 
Table 1. Primer sequences.

\begin{tabular}{ll}
\hline Primer & \multicolumn{1}{c}{ Sequence $\left(5^{\prime}\right.$ - $^{\prime}$ ) } \\
\hline AGP1 & GGA TCG ARA ACA CVA CAN AYC G \\
AGP2 & GYY TCT TGY TGG TAR WAC TG \\
AGP3 & TGA GGA ATC TGA GCA GGC TTT C \\
AGP4 & CGT CAG GTC ACT TTC TGT AAG C \\
AGP5 & GAC ACT GTC GTT GGC ATA TTC A \\
AGP6 & CTT GCT CAA GAA GGC CTA TGA A \\
AGP7 & ATG GCA TTG CAG AGT GAT CA \\
AGP8 & TCA GAC TAA TTG AAG AGG TGG C \\
AtAG1 & AGG CAA TTG ATG GGT GAG AC \\
AtAG2 & TGG ATC GGA TTC GGG TAA TA \\
AtActin1 & GTC GTA CAA CCG GTA TTG TGC TG \\
AtActin2 & CCT CTC TCT GTA AGG ATC TTC ATG AG \\
\hline
\end{tabular}

3

4

5

6

7

8

9

10 
1 Table 2. Flowering times of wild-type and transgenic Arabidopsis.

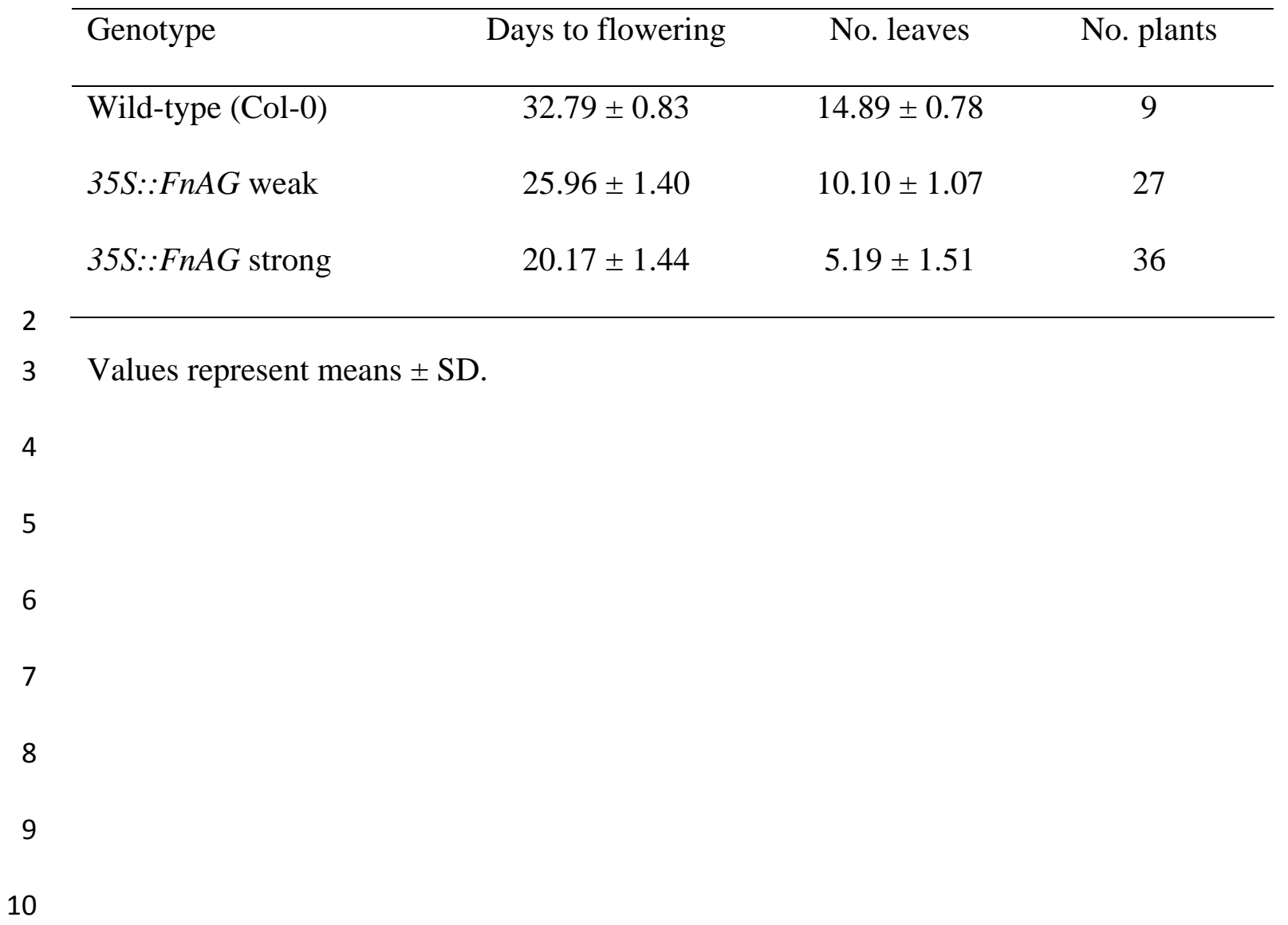

11

12

13

14

15

16

17

18

19

20 


\section{Figure Legends}

2 Fig. 1 Gene structure and deduced amino acid sequence alignment of an AGAMOUS ortholog in

3 black ash (FnAG). (a) FnAG gene structure. Exons are depicted s black boxes and introns by

4 lines. The triangles represent the position of start and stop codons. (b) Alignment of deduced

5 amino acid sequences encoded by $F n A G$ with $A G$ homologs from a range of woody plant species.

6 Identical amino acid residues in relation to FnAG are black and conserved residues are in gray.

7 Dots indicate gaps inserted for alignment optimization. The amino acid terminal extension (N),

8 MADS, intervening (I), keratin-like (K), and carboxyl terminal (C) regions are marked. Motifs I

9 and II within the $\mathrm{C}$ region were indicated.

10 Fig. 2 Phylogenetic analysis of MADS-box proteins by the neighbor-joining method. The

11 bootstrap confidence values (\%) from 1000 replicates are indicated on the branches. The scale at

12 the bottom indicates genetic distance proportional to the amino acid substitutions per site.

13 Fig. 3 Expression pattern of $F n A G$ in various tissues of black ash by (a) Semi-quantitative RT-

14 PCR analysis and (b) real-time PCR analysis. F, female flowers; M, male flowers; L, leaves; and

$15 \mathrm{~S}$, in-vitro shoot cultures. The translation elongation factor alpha $(e E F 1 \alpha)$ gene was used as a

16 constitutively expressed control. Each reaction had three biological replicates and was repeated

17 two times. Error bars represent the standard deviation.

18 Fig. 4 Floral and vegetative morphology of Arabidopsis. (a) Wild-type flower. Transgenic

19 flowers overexpressing $F n A G$ under the $35 \mathrm{~S}$ promoter showed homeotic mutations in the first

20 and second whorls including (b) stamen-like petals, or (c) sepals converted into carpel-like

21 structures. (d) Curled transgenic cauline leaf entrapping the lateral inflorescence. (e) Immature

22 early flowers showing failure of the sepals to enclose flower buds. (f) Extremely small size 
1 transgenic plant with early bolting. Arrow indicates floral buds. Thirty-one-day-old (g)

2 transgenic, (h) wild-type, and (i) empty vector control plants.

3 Fig. 5 Phenotypes of transgenic Arabidopsis $(35 S: \because F n A G)$ plants with (a) strong or (b) weak

4 phenotypic alterations compared to (c) wild-type plant.

5 Fig. 6 Relative expression levels of (a) ectopically expressed $F n A G$ and (b) endogenous $A t A G$ in

6 wild-type (Col-0) and transgenic Arabidopsis. Expression levels were normalized to AtActin2.

7 Each reaction had three biological replicates and was repeated twice. Error bars represent the

8 standard deviation. 
(a)

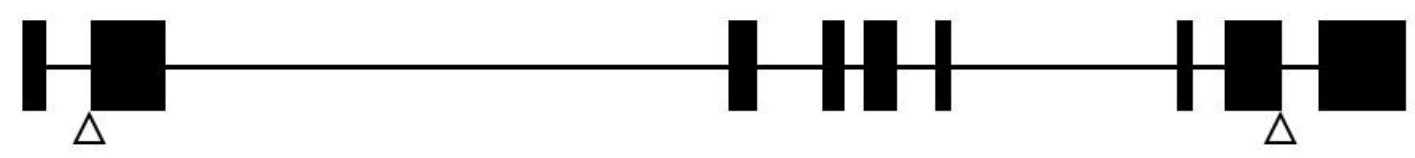

(b)

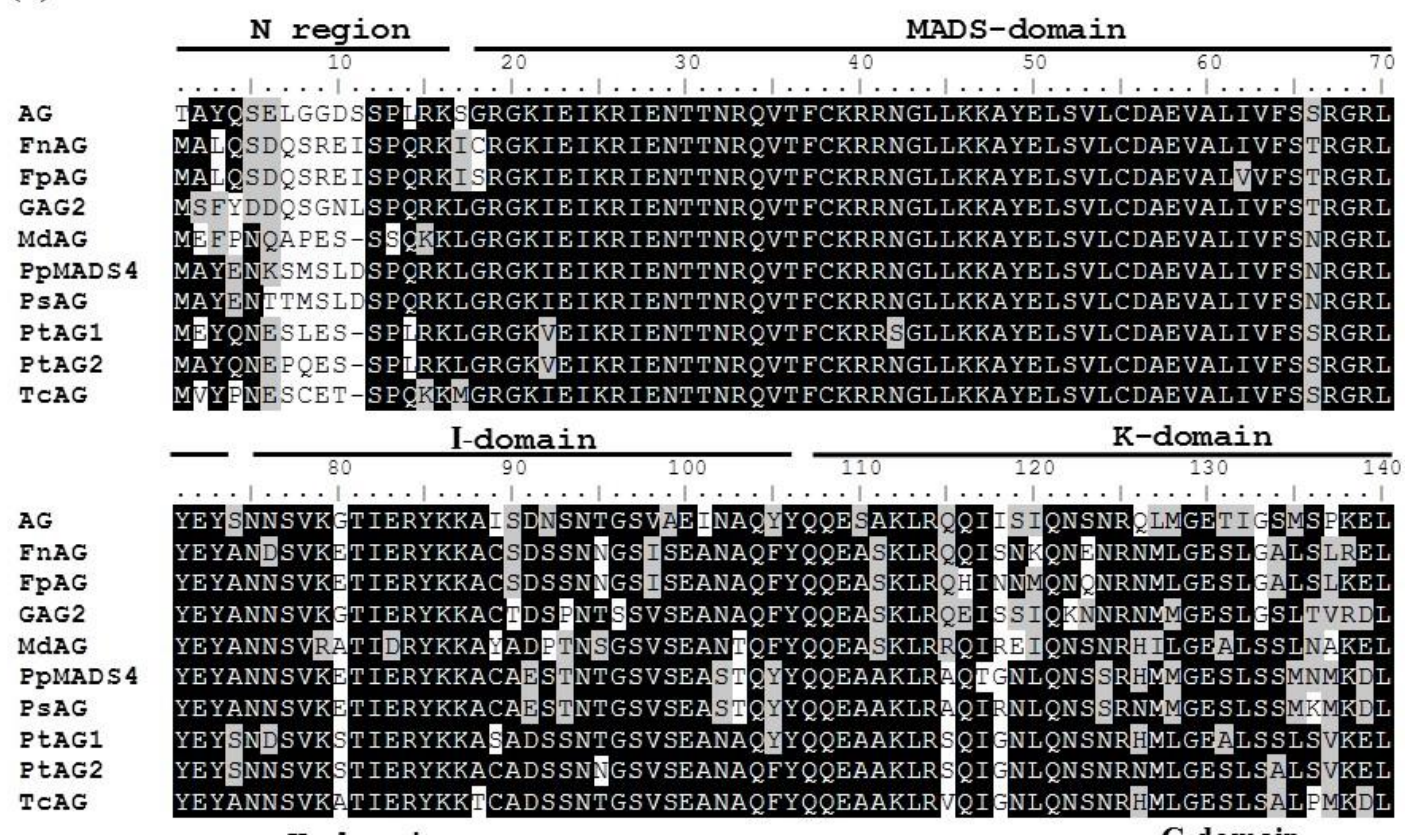
$\mathrm{K}$-domain

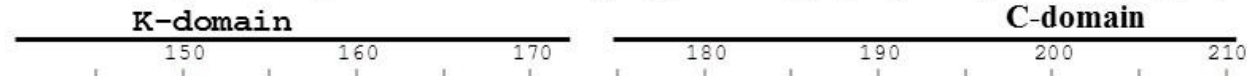

AG

FnAG

FPAG

GAG 2

MdAG

PpMADS 4

PSAG

PtAG1

PtAG2

TCAG

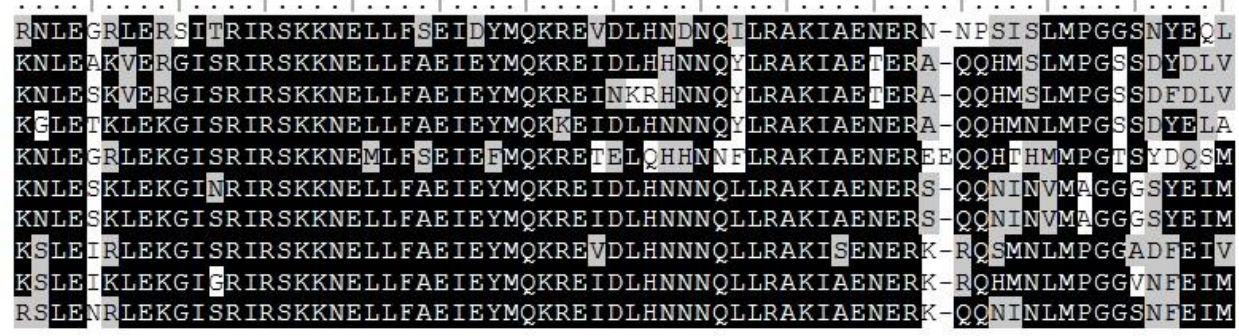

\section{C-domain}

AG

FnAG

FpAG

GAG2

MdAG

PPMADS 4

PSAG

PtAG1

PtAG2

TCAG

\begin{tabular}{cccc}
\multicolumn{3}{c}{ C-domain } & \\
\hline 220 & 230 & 250
\end{tabular}

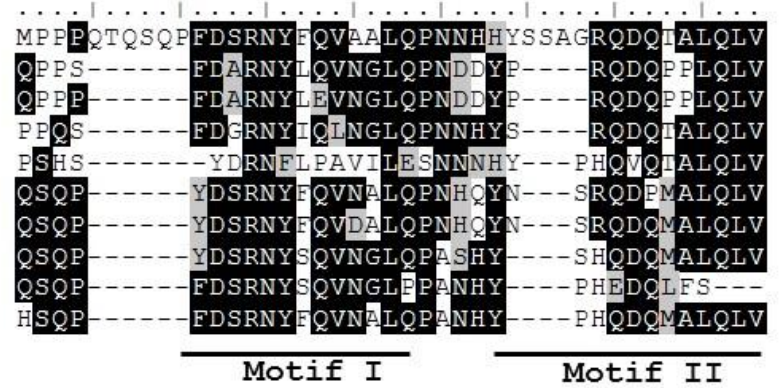




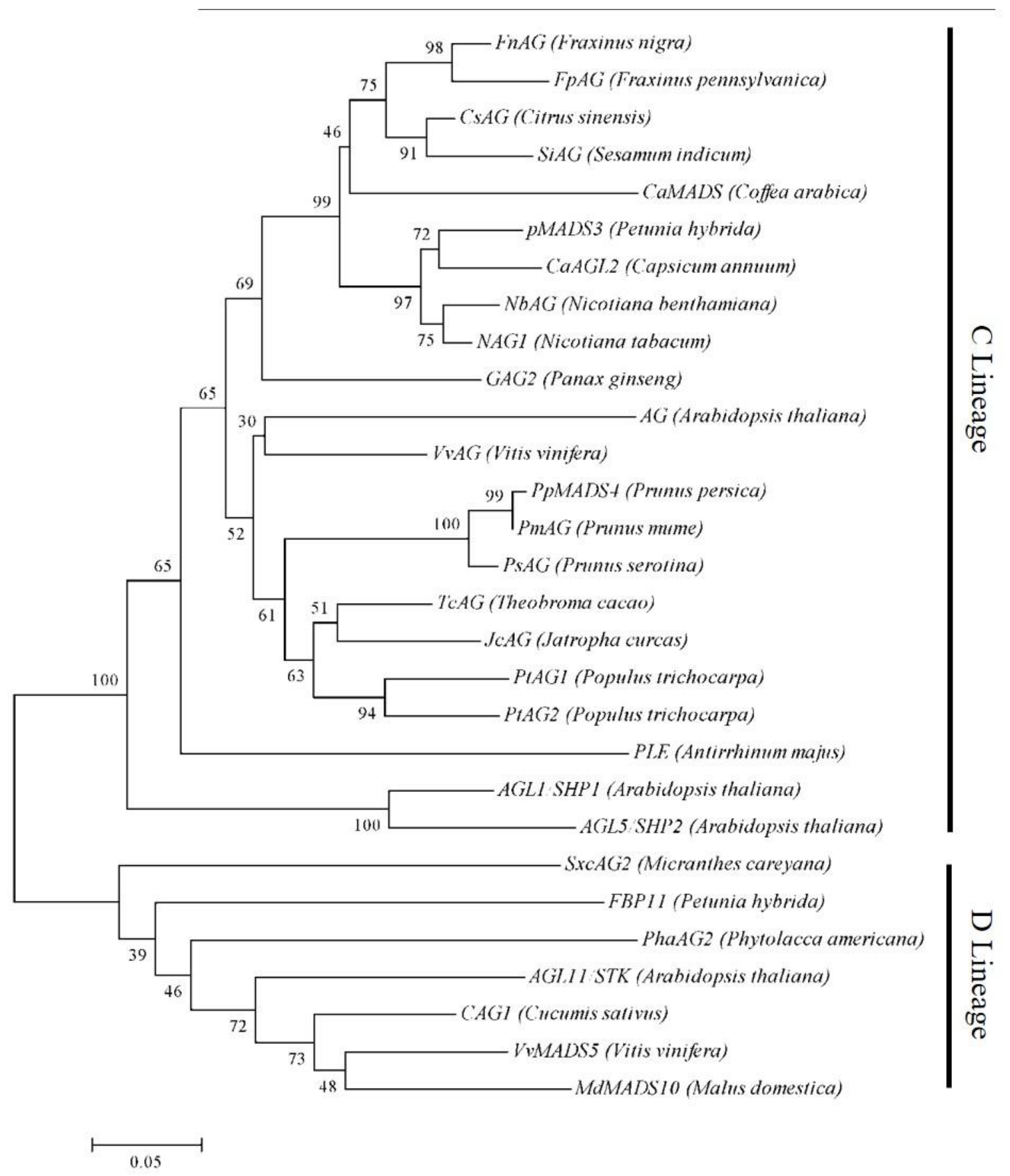


(a)

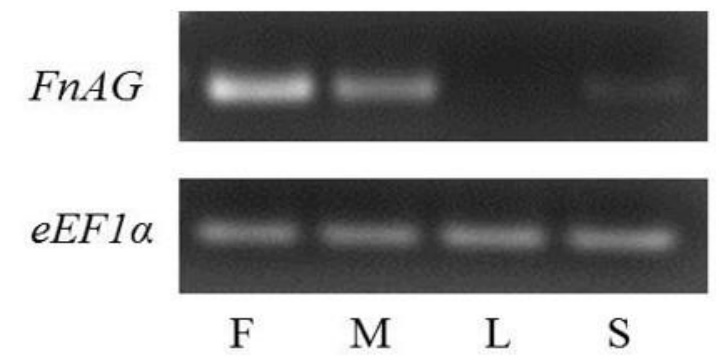

(b)

FnAG

1

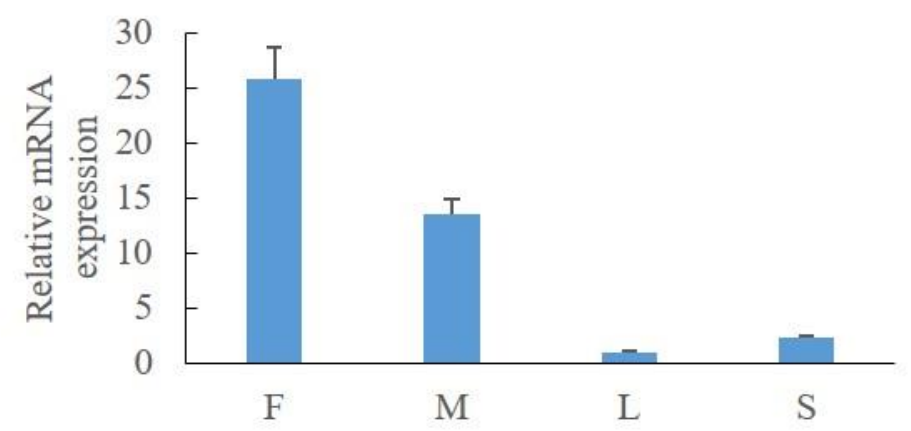



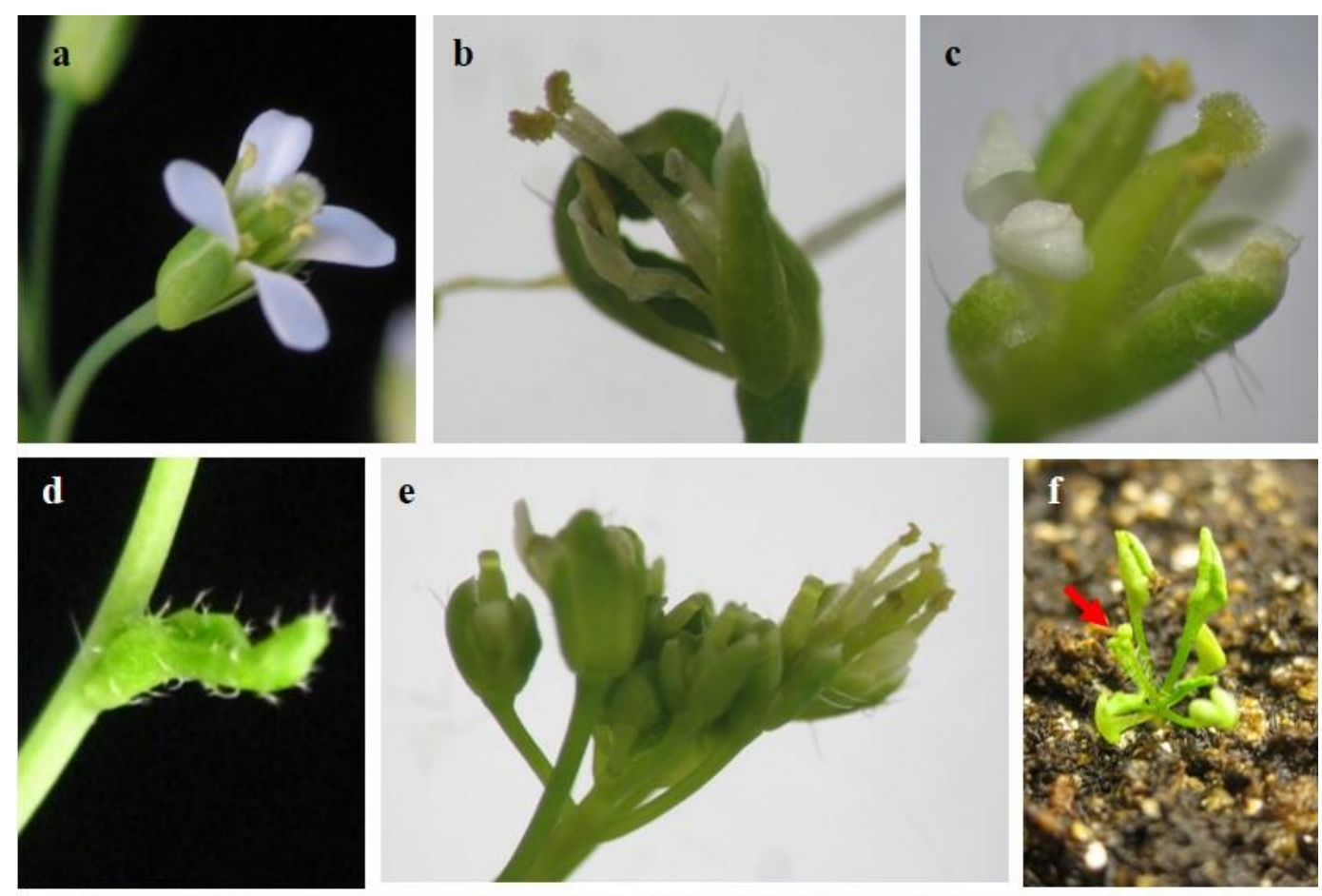

1

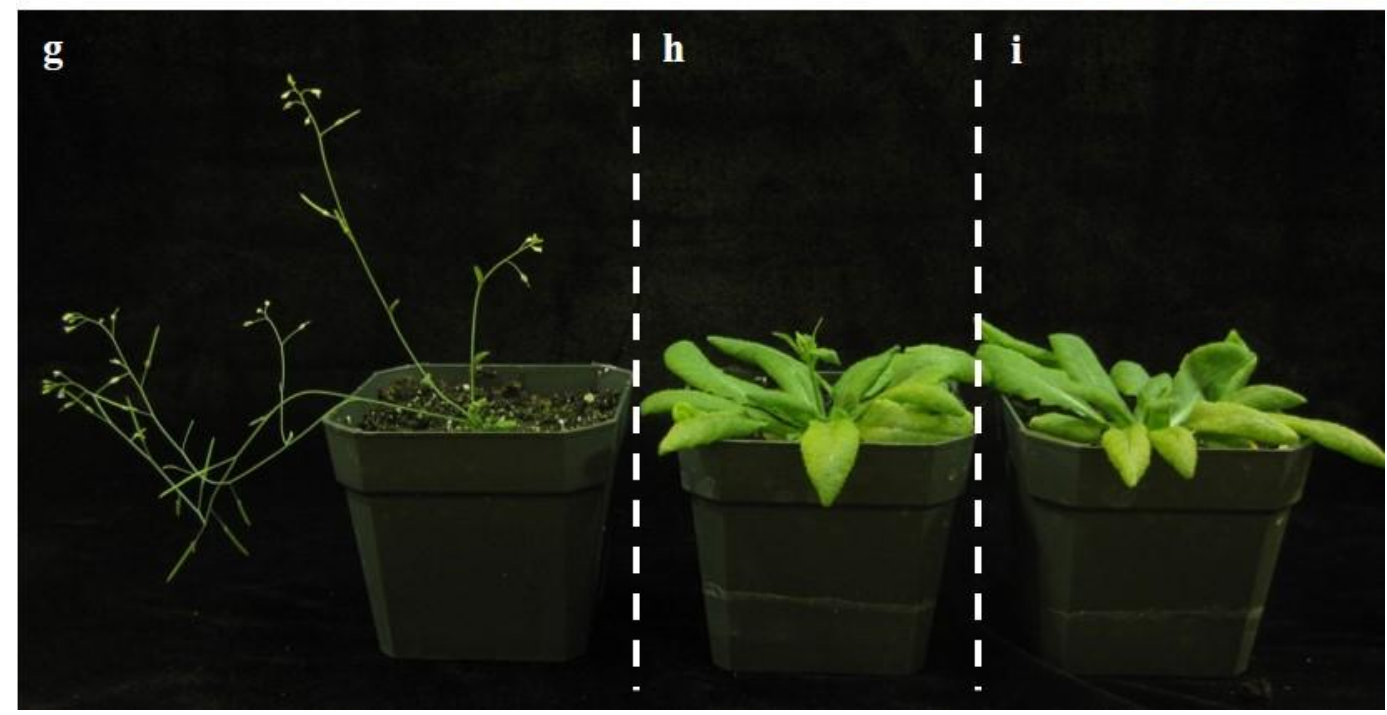

2 


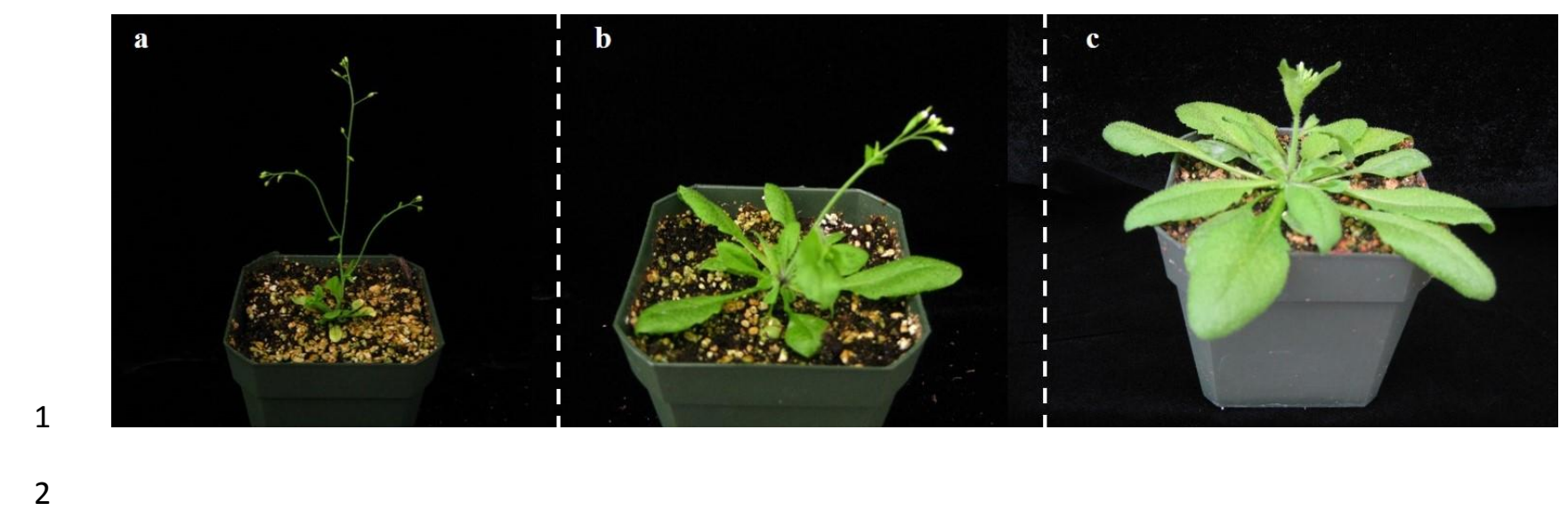


(a)

$F n A G$

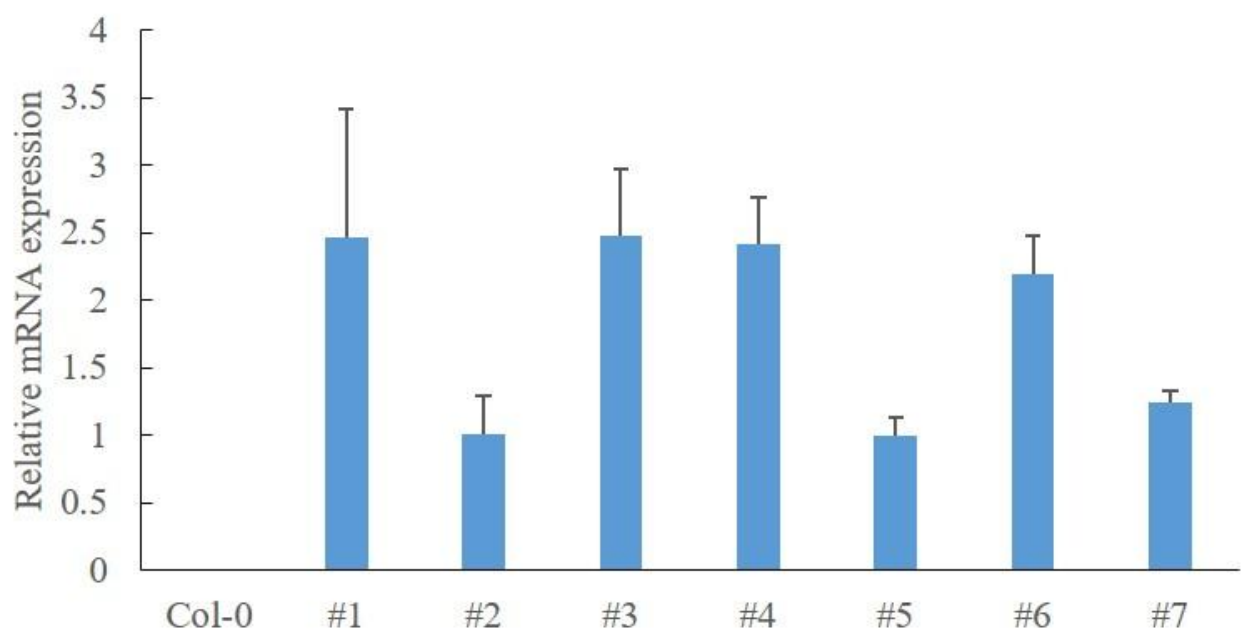

(b)

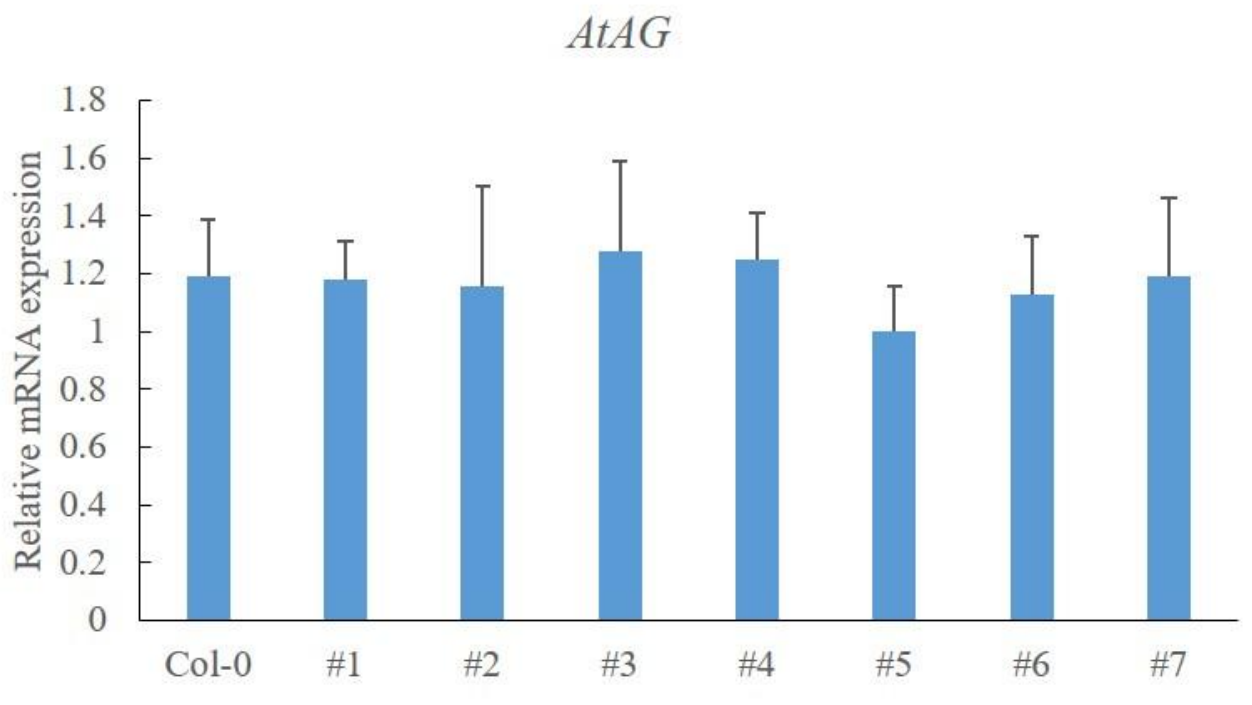

